\title{
Erratum to: Reoperation after mitral valve repair in viewpoints of kidney injury as well as hemolytic anemia
}

\author{
Ryo Ishida · Takaomi Adachi $\cdot$ Yayoi Shiotsu • \\ Mami Ishida • Yasukiyo Mori · Kiyoshi Doi • \\ Keiichi Tamagaki
}

Published online: 24 January 2015

(C) Japanese Society of Nephrology 2015

\section{Erratum to: CEN Case Rep \\ DOI 10.1007/s13730-014-0152-Z}

The original version of this article unfortunately contained a mistake.

In Table 3, Renal information of "Our case" should be Cr1.48, not CM.48.

The online version of the original article can be found under doi:10.1007/s13730-014-0152-z.

R. Ishida $(\varangle) \cdot T$. Adachi · Y. Shiotsu $\cdot$ M. Ishida ·

K. Tamagaki

Division of Nephrology, Kyoto Prefecture University of

Medicine, 465 Kajii-cho, Kamigyou-ku, Kyoto, Japan

e-mail: ryoishi2006@yahoo.co.jp

\section{Y. Mori}

Division of Nephrology, Saiseikai Izuo Hospital,

3-4-5 Kitamura, Taisyo-ku, Osaka, Japan

K. Doi

Division of Cardiovascular Surgery, Kyoto Prefecture University

of Medicine, 465 Kajii-cho, Kamigyou-ku, Kyoto, Japan 